\title{
EDITORLAI NOTB
}

Due to technical problems, the transcripts of the discussion recordings were incomplete and occasionally damaged. The editors tried their best to correct for this. It cannot be excluded, though, that in a few cases our printed version does not fully reflect what the speaker intended to state. The editors apologize for this.

Even more regrettable is that for a major part of the contributions the discussions have been lost entirely. This may lead to the impression that no discussions took place, whereas the opposite was the case: there was not a single contribution without discussion. The editors apologize to the authors concerned.

The editors are happy that John Drilling and Phil Hill agreed to compile a list of objects which is reproduced in the Annex. In view of the many newly discovered hellum stars, the reports of which are scattered in literature, such a list appears especially important and will add to the value of this volume. 


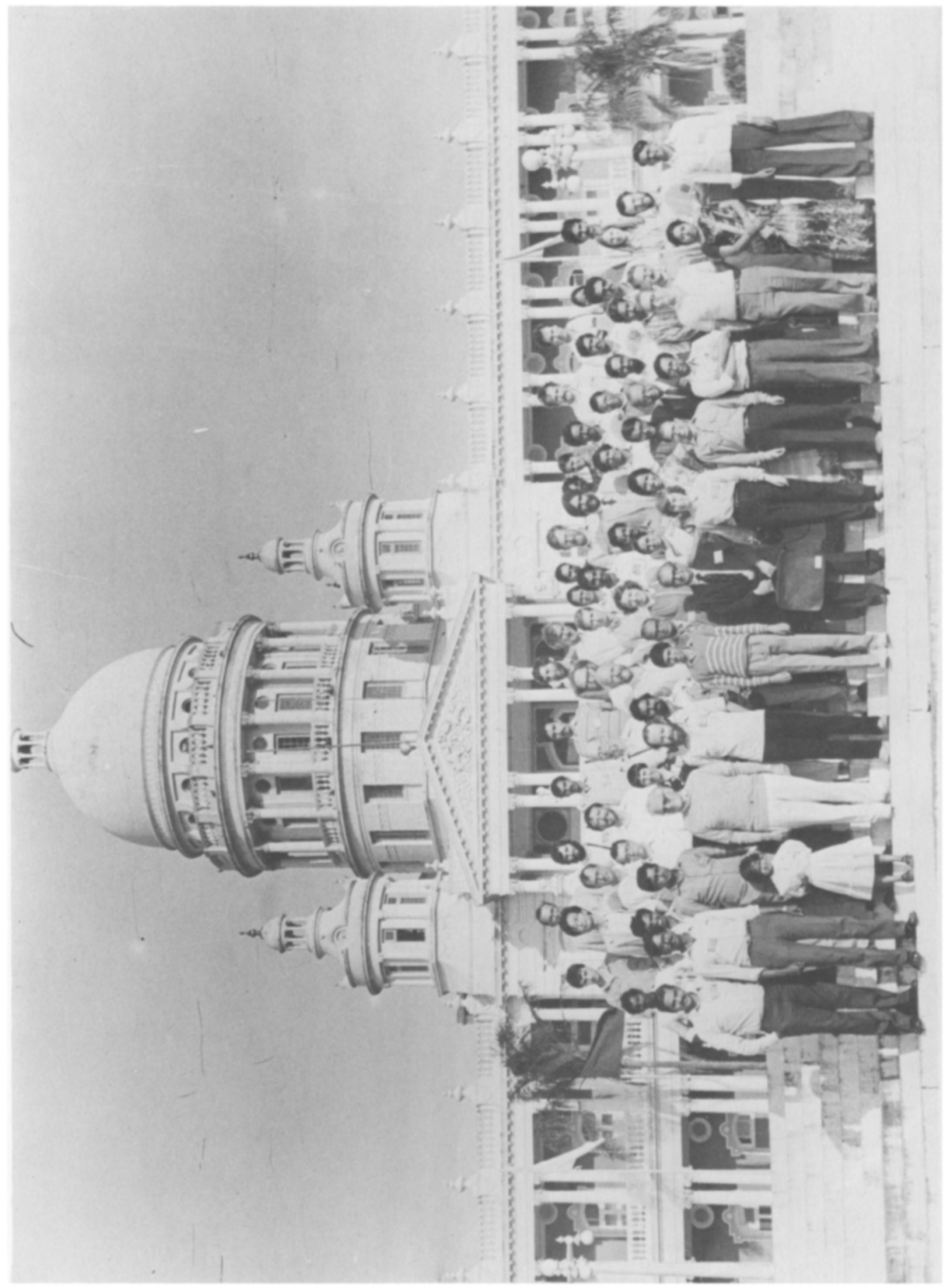


(5)

(8)
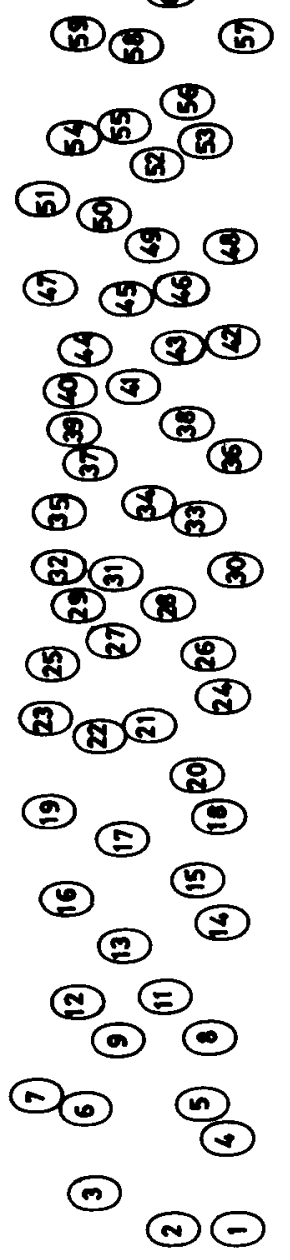

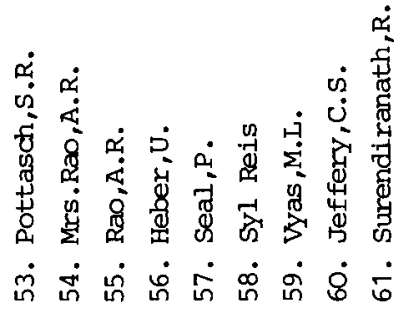

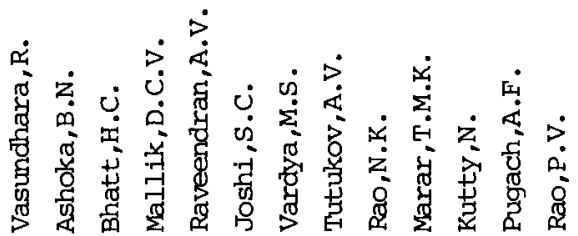

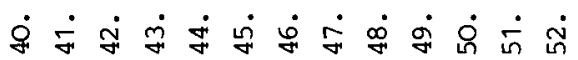

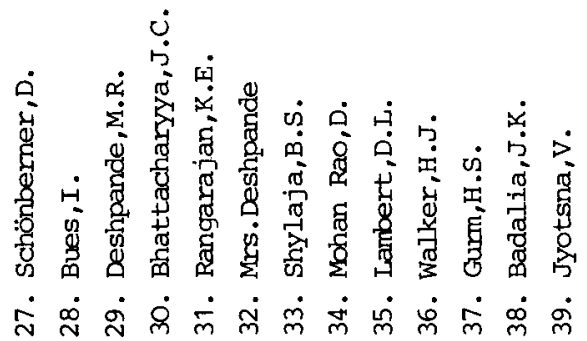

